\title{
A UNIVERSIDADE E O SEU PAPEL PARA A PROMOÇÃO DA PAZ: A EXPERIÊNCIA DA AÇÃO DE EXTENSÃO DE YOGA E CULTURA DE PAZ NA FACULDADE DE EDUCAÇÃO DA UNIVERSIDADE FEDERAL DO CEARÁ
}

\author{
THE UNIVERSITY AND ITS ROLE FOR THE PROMOTION OF PEACE: \\ AN EXTENSION EXPERIENCE OF YOGA AND CULTURE OF PEACE AT \\ FACULDADE DE EDUCAÇÃO OF THE UNIVERSIDADE FEDERAL DO \\ CEARÁ
}

\author{
Pricila Cristina Marques Aragão \\ Kelma Socorro Lopes de Matos ${ }^{* *}$
}

\begin{abstract}
RESUMO
O artigo busca refletir sobre a ação de extensão intitulada "Yoga e Cultura de Paz na FACED", pertencente ao Projeto de Extensão em Cultura de Paz na FACED: Ações de Educação, Espiritualidade e Saúde, coordenado pela Prof. Dr. ${ }^{a}$ Kelma Socorro Lopes de Matos, como uma iniciativa promotora da paz e da saúde mental, nos âmbitos individual, interpessoal e coletivo. A investigação qualitativa se baseou na pesquisa ação, utilizando para este artigo, dois questionários como instrumentos para a obtenção de dados. O objetivo do trabalho é entender como o yoga pode promover uma cultura de paz no ambiente, minimizando ou sanando os problemas e dificuldades relacionados a esse local, como o estresse psicoemocional da comunidade acadêmica. Os resultados mostram que tal prática integrativa, de fato, auxilia os seus praticantes a lidarem com momentos difíceis e buscar o autoconhecimento como forma de desenvolver uma vida equilibrada através da união entre saúde física, mental e emocional.
\end{abstract}

Palavras-chave: Cultura de Paz. Ação de Extensão. Yoga. Espiritualidade.

\begin{abstract}
The article seeks to reflect on the extension action entitled "Yoga and Culture of Peace at FACED", belonging to the Extension Project in Culture of Peace at FACED: Actions of Education, Spirituality and Health, coordinated by Prof. Dr. Kelma Socorro Lopes de Matos, as an initiative promoting peace and mental health in the individual, interpersonal and collective spheres. The qualitative research was based on action research, using for this article, two questionnaires as instruments for obtaining data. The goal of this work is to understand how yoga can promote a culture of peace in the environment, minimizing or healing the problems and difficulties related to this place, such as the psychoemotional stress of the academic community. The results show that such integrative practice actually helps practitioners deal with difficult times and seek self-knowledge as a way of developing a balanced life through the union of physical, mental and emotional health.
\end{abstract}

Keywords: Culture of Peace. Extension Action. Yoga. Spirituality.

\footnotetext{
*Bióloga (UFC), Mestre em Desenvolvimento e Meio Ambiente (PRODEMA-UFC), Doutoranda do PPGE da Faculdade de Educação da Universidade Federal do Ceará (UFC), Professora de Yoga e Artesã. E-mail: pricila_aragao@hotmail.com

** Professora titular do Departamento de Fundamentos da Educação da Universidade Federal do Ceará (UFC) e do Programa de Pós-Graduação em Educação (UFC). Mestra e Doutora em Educação. Pós-Doutorado em Educação (UFBA, 2011).Cursando estágio Pós Doutoral no Centro de Estudos Sociais (CES), da Universidade de Coimbra. Supervisão Profa Dra Teresa Cunha. E-mail: kelmatos@uol.com.br
} 
"O silêncio é o único meio para trazer a paz. Uma vez que sua mente está em silêncio, tudo fica silencioso e sereno. Então, todo o conceito, o propósito de fazer yoga é trazer silêncio, para trazer paz à sua mente.

Quando se está praticando silenciosamente, se gera uma certa energia, que torna todo o ambiente pacífico."

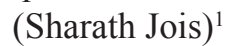

\section{INTRODUÇÃO}

Em nossa sociedade o saber racional é supervalorizado, como indica Duarte Jr. (2001), pois se destaca a ilusória separação entre corpo, mente e espírito, levando-nos a uma educação racionalista que muitas vezes desconsidera outras dimensões do Ser (como a física, a mental e espiritual, por exemplo) o que pode gerar desequilíbrios de ordem psicofísica, como estresse emocional, transtorno de ansiedade, depressão e transtornos alimentares. $\mathrm{O}$ autor propõe um estímulo à educação do sensível, ou seja, de modelos educacionais capazes de estimular todas as dimensões dos indivíduos para tornar possível o desenvolvimento dos saberes, de modo mais equânime.

A universidade é geralmente percebida como a sede do conhecimento racional, privilegiando ações e relações que giram entorno dessa esfera pautada na racionalidade, porém tal perspectiva começa a ser discutida e mudada na medida em que percebemos o quão importante é humanizar as relações acadêmicas e permeá-las com a possibilidade de desenvolver também o lado físico, emocional e espiritual das pessoas. A própria existência de pesquisas sobre cultura de paz e espiritualidade, por exemplo, abrem uma nova perspectiva para o ambiente acadêmico, trazendo as demais esferas do desenvolvimento humano para o espaço da universidade.

Os resultados encontrados nos estudos conduzidos por Levecque et al. (2017) e Evans et al. (2018) demonstram que os alunos de pós-graduação possuem seis vezes mais chances de experimentar depressão e ansiedade em comparação com a população em geral. Os autores afirmam que há uma crise na saúde mental

\footnotetext{
1 "Silence is the only method to bring peace. Once your mind is silent then everything becomes silent and serene. Then whole concept, the purpose of doing yoga is to bring silence, to bring peace to your mind. When they are silently doing practice, it generates a certain energy, which makes the whole environment peaceful". (HENDRY, 2017, p.2)
}

dos estudantes, e que é preciso criar estratégias para fomentar o cuidado nos espaços acadêmicos. Sugerem ainda que é necessário criar programas direcionados à saúde mental dos estudantes que os ajudem a entender a dinâmica entre o trabalho e a vida pessoal. Por fim, apontam a importância de mudanças no ambiente da academia, tornando-o mais salutar para que possa diminuir a incidência de doenças mentais, a partir de uma nova cultura acadêmica (WOOLSTON, 2016, 2017, 2018).

Powell $(2017,2018)$ afirma que o ambiente competitivo, a incerteza com relação ao futuro, as relações interpessoais potencialmente conflitantes entre colaboradores e rotinas que demandam intenso trabalho mental podem contribuir negativamente para o bem-estar dos pesquisadores. Para equilibrar essas questões, sugere uma mudança na percepção com ambiente acadêmico, tornando-o inclusivo e com práticas visando estimular outros valores, como a bondade. Para isso, aponta a criação de grupos de suporte, permitindo o desenvolvimento de um senso de comunidade capaz de fortalecer laços entre as pessoas e torná-las capazes de amparar umas as outras.

Dentre os modos em que pode-se estimular o florescimento desse sentimento de comunidade, a cultura de paz pode agir como facilitadora no resgate da percepção integral e saúde física e mental do indivíduo, para que, ao se sentir completo e equilibrado em sua essência, possa promover a paz entre seus pares e o meio em que vive. Desse modo, trabalha-se para a construção da paz, simultaneamente, em três âmbitos: individual, interpessoal e coletivo, por acreditar-se que tais dimensões são indissociáveis. Portanto, a paz é uma construção crítica, ativa e engajada no rompimento de barreiras para a construção de pontes entre seres humanos e o mundo.

A cultura de paz se baseia nos conhecimentos intrínsecos ao ser humano, como a solidariedade, amorosidade e o diálogo, porém, essas características precisam ser estimuladas para que possam crescer e aflorar adequadamente. Entendemos que a paz é uma construção individual e coletiva, sendo impossível apartar essas duas dimensões, construídas simultaneamente, e de forma dialógica. Para que isso seja possível, é preciso romper com a perspectiva de passividade, comumente (e equivocadamente) atribuída à ideia de paz, ao assumirmos a sua composição crítica, 
ativa e engajada no desenvolvimento entre seres humanos e o mundo.

Segundo Guimarães (2011), a educação para a paz é determinante para a efetivação de uma cultura de paz. O autor passa a desvelar nove tradições que sinalizam a pluralidade manifestada dos vários tipos de educação voltados para a paz, sugerindo ainda que se use o termo "educações para a paz", na tentativa de tornar visível os diversos caminhos possíveis, pois para ele, "a educação para a paz é um campo, um campo aberto, um mar mesmo, onde não há lugar para restrições ou reduções" (GUIMARÃES, 2011, p. 320).

Pensando nisso, este artigo se propõe a relatar a experiência e dialogar (através dos testemunhos dos participantes) sobre a promoção da paz e da saúde mental no ambiente acadêmico, especificamente, através do cotidiano da extensão universitária. Trazemos os dados da Ação de extensão intitulada Yoga e Cultura de Paz na FACED - UFC, que representa uma das ações desenvolvidas no Projeto de Extensão em Cultura de Paz na FACED/UFC (Faculdade de Educação da Universidade Federal do Ceará): Ações de Educação, Espiritualidade e Saúde, coordenado pela Prof. ${ }^{a}$ Dr. ${ }^{a}$ Kelma Socorro Lopes de Matos.

O projeto de extensão se iniciou em 2016 e segue ativo pelo terceiro ano consecutivo, em 2018. Cada ação de extensão tem duração, público e metodologia próprios, de acordo com suas especificidades e objetivos inerentes a cada prática promotora da saúde e da paz. As demais ações são: Formação de educadores em Cultura de Paz; Valores humanos para fazer florescer uma Cultura de Paz; Reiki na FACED; Vivendo Valores na Educação; e Tecendo mandalas, construindo a Paz na FACED.

A ação de extensão em "Yoga e Cultura de Paz na FACED”, especificamente, interliga os saberes do yoga e da espiritualidade como construtores de espaços onde a cultura de paz possa ser disseminada e discutida, de modo que essa cultura seja apropriada pelo indivíduo e propagada para suas relações pessoais, interpessoais e na sua forma de se projetar e interagir no mundo.

O objetivo desse artigo é, portanto, pensar em como a cultura de paz pode auxiliar no bem-estar e no desenvolvimento integral do ser humano na academia, evitando os problemas e dificuldades relatados anteriormente, ao incitar uma nova lógica na produção científica, amparada por valores humanos e fortalecida por grupos de apoio capazes de orientar e sustentar uma prática científica saudável, produtiva e reflexiva.

No próximo tópico, relativo ao referencial teórico, abordaremos como o yoga e a cultura de paz são entendidos nessa ação de extensão discorrendo e problematizando sobre os benefícios de aliar os dois conceitos no contexto específico do ambiente académico. A seguir, na metodologia, descreveremos a ação de extensão em detalhe, de modo a situar o leitor nos pressupostos e particularidades da pesquisa. No tópico seguinte, traremos os resultados, como o perfil dos seus participantes e inserindo a discussão sobre a promoção da paz pautada em depoimentos dos envolvidos na ação e refletindo sobre o impacto positivo da extensão no cotidiano dos mesmos. Por fim, na conclusão, o último tópico, realizaremos uma reflexão acerca do projeto enquanto promotor de uma educação para a paz na universidade.

\section{A RELEVÂNCIA DO YOGA E DA CULTURA DE PAZ}

Para Hermógenes (2010), o yoga é o caminho para a integração do indivíduo, que graças ao estilo de vida das grandes cidades, encontra-se desconectado de si, dos outros e do universo, pois o atual modo de viver provoca desequilíbrios manifestados no corpo físico, na saúde mental, no modo de se relacionar com a sociedade e no âmbito espiritual do ser humano. As alterações no modo de vida fizeram com que perdêssemos o contato com nossa essência e a capacidade de perceber as sutilezas do nosso próprio ser.

A ideia de inserir o yoga no meio acadêmico dialoga com o princípio que reconhece o indivíduo em sua completude, através do estímulo ao autoconhecimento como caminho para o equilíbrio interior, que tende a se propagar para os contatos com a sociedade e com o mundo, trazendo uma maneira mais amorosa e crítica de perceber o papel que desempenhamos na sociedade.

A prática de yoga feita regularmente pode beneficiar o indivíduo pelo fortalecimento muscular, aumento da flexibilidade, estímulo ao bom funcionamento de órgãos internos, regulação do funcionamento hormonal, promoção de clareza mental, estímulo à respiração natural, tranquilização da mente, estímulo ao vigor mental e aumento da percepção do corpo, 
mente e sentimentos (ARORA, 2013; BROWN, 2011; HERMÓGENES, 2007; PACKER, 2009). Porém, seus benefícios transcendem o aspecto físico ao se fundamentarem no desenvolvimento espiritual dos praticantes, estimulando e ressignificando o entendimento de se estar no mundo

Uma vez que o yoga é acessível a todas as pessoas independentemente de origem, formação ou religião e pode ser praticado por homens, mulheres, sadios ou doentes, sem limites de idade (HERMÓGENES, 2007; IYENGAR, 2007; JOIS, 2010), os pesquisadores começaram investigar suas potencialidades e benefícios no campo da educação, ambiente rico de potencialidades e contradições, que poderia ser transformado positivamente com a inserção de práticas de autoconhecimento como yoga e meditação em seus interstícios. Arenaza (2004, p. 14) justifica a inclusão de práticas de yoga no cotidiano escolar na medida em que:

O ensino tradicional desvincula o corpo e a mente no processo de aprendizagem. Mas o yoga, por definição, se fundamenta nesta união. Assim, o corpo age como um trampolim para a aprendizagem, mas a mente também ajuda a revitalizar o corpo. A forma de empregar o yoga que nos transmite Patanjali age em ambos os sentidos, e sugere a alternância do intenso trabalho mental com relaxamentos e exercícios físicos, porém tendo grande cautela nas transições entre o trabalho mental e físico (ARENAZA, 2004, p. 14).

Assim, o yoga pode contribuir beneficamente para o bem-estar e qualidade de vida de alunos, professores e toda a comunidade escolar, uma vez que no ambiente educativo somos submetidos a ansiedade, ao estresse, ao excesso de atividades intelectuais, ao pouco estímulo às atividades físicas e ao neglicenciamento da auto-observação. Tal contribuição do yoga seria feita através das habilidades e ferramentas necessárias para lidar com situações estressantes, como o controle da ansiedade, a promoção da calma e da clareza mental, a liberação de tensões físicas e psicológicas, a geração de ambientes mais saudáveis para o trabalho educacional e o estímulo constante ao autoconhecimento.

$\mathrm{O}$ yoga se situa enquanto um processo de busca espiritual na medida em que a "Espiritualidade é o processo de expandir continuamente a percepção de nós mesmos, até que possamos reconhecer que somos uma fonte eterna de amor. Através do reconhecimento dessa verdade, podemos atingir a paz interior que procuramos." (BABA, 2014, p. 38). Assim, a espiritualidade faz parte das dimensões que precisam ser desenvolvidas em cada ser, igualmente com as demais, sejam elas físicas, psicológicas e emocionais, como um processo integrado de autoconhecimento, objetivando a unidade e integração de cada indivíduo para que este, ao se sentir pleno, possa atuar no mundo com consciência e criticidade, em prol do desenvolvimento coletivo.

Contudo, requer-se sensibilidade para entender as diversas manifestações da busca espiritual, e não somente os processos de ligação com a espiritualidade conectados com as religiões. Uma vez que esse processo envolve três grandes dimensões, buscando a integração nos níveis: individual (através do autoconhecimento), do bom relacionamento com os outros (através de práticas coletivas de cuidado e bem-estar espiritual coletivo) e da integração com o aspecto divino, podemos perceber a multiplicidade de caminhos disponíveis na busca espiritual.

A Cultura de Paz sustenta esse trabalho por acreditarmos que ela é indissociável de uma práxis verdadeira da espiritualidade e do yoga, por basear-se na construção da paz em seus níveis individual e coletivo. É importante evidenciar que o conceito de paz aqui trabalhado baseia-se no pensamento de Jares $(2002 ;$ 2005), percebendo-a de acordo com a concepção positiva e diretamente relacionada aos conceitos de justiça social, direitos humanos e democracia (FREIRE, 2011a; 2011b; 2014), bem como na resolução de conflitos como forma de crescimento interpessoal e renegando os processos de violência, seja ela direta, indireta ou estrutural, e por tais motivos construindo a paz ativa, crítica, engajada, e jamais associada à passividade ou inércia.

É na busca por coerência em nosso fazer cotidiano que incorporamos a cultura de paz no ambiente educativo, como forma de disseminar e estimular atitudes positivas para lidar com os conflitos, as contradições e a pluralidade de atos e opiniões aos quais estamos submetidos no dia a dia. Pensar em uma cultura de paz nos espaços acadêmicos é valorizar as diferenças e estimular o diálogo, reconhecendo que cada leitura da realidade é uma peça de um quebra-cabeça multicolor. No tópico a seguir, descrevemos 
a ação de extensão bem como a metodologia utilizada nos encontros.

\section{METODOLOGIA: A AÇÃO DE EXTENSÃO}

A ação de extensão intitulada Yoga e Cultura de Paz na FACED/UFC buscou refletir sobre a incorporação do yoga e da espiritualidade como caminhos para a construção de uma Cultura de Paz no ambiente acadêmico (em especial, na Faculdade de Educação da Universidade Federal do Ceará), através das vivências teórico-práticas enraizadas nesses três ramos de conhecimento (Yoga, Espiritualidade e Cultura de Paz).

A pesquisa possuiu cunho qualitativo, pois se preocupou em compreender fenômenos humanos, práticas e relações que perpassam a subjetividade humana (MINAYO, 2010). A valorização do diálogo e das relações interpessoais ajudam a caracterizar outro aspecto fundante do trabalho, partindo da dialogicidade proposta e vivida por Freire (2011a) para sustentar o encontro de experiências e estimular a construção de saberes coletivos significantes e críticos.

Nos inspiramos na pesquisa ação (THIOLLENT, 2011) que segundo Gil (1999), é caracterizada pelo envolvimento do pesquisador no processo da pesquisa, como um observador participante, porém indo além, ao vivenciar ativamente da coleta, análise e interpretação de dados. De acordo com Oliveira (2008, p. 74), "a pesquisa ação requer o compromisso do pesquisador com a população pesquisada a fim de buscar coletivamente alternativas para resolução dos problemas que afligem essas pessoas ou, mais precisamente, a comunidade pesquisada". Segundo Matos \& Vieira (2001) e Thiollent (2011), esse tipo de pesquisa pressupõe uma ação planejada, com o interesse não de apenas verificar os fatos e sim de transformar a realidade, estimulando mudanças e transformações no âmbito individual, interpessoal e comunitário.

Para isso, foram ofertadas aulas de yoga (duas vezes por semana) para a comunidade (alunos, servidores, professores e membros externos à universidade) de acordo com o calendário acadêmico da UFC, por quatro semestres seguidos (de 2016.1 a 2017.2). Cada encontro possuía duração de 90 min (noventa minutos), organizados em 30 min (trinta minutos) de discussão teórica e 60 min (sessenta minutos) de aula prática, com exceção do primeiro semestre, quando haviam três turmas com a duração de 60 min (sessenta minutos) de aula prática. Em média, foram realizados 24 encontros por semestre, com uma média de 73 horas/aula por semestre. Os detalhes estão descritos na Tabela 1.

Para a participação na ação de Yoga e Cultura de Paz na FACED, os interessados preencheram uma ficha de inscrição com informações pessoais gerais e perguntas sobre a prática de yoga (se já conheciam o yoga, eram praticantes ou não, o que esperavam das aulas e haviam realizado estudos teóricos sobre o tema, por exemplo) disponibilizada através do endereço eletrônico do Grupo de Pesquisa em Cultura de Paz, Juventudes e Docentes da UFC (http://ufcculturadepaz.webnode.com.br) coordenado pela professora Dr. ${ }^{a}$ Kelma Matos. O critério seletivo usado para a convocação dos estudantes foi o preenchimento de vagas ofertadas a cada semestre, formando-se uma lista de espera na qual os alunos eram chamados a participar das aulas, à medida que novas vagas eram disponibilizadas.

Quadro 1: Descrição geral das Aulas de Yoga na FACED

\begin{tabular}{|c|c|c|c|c|c|}
\hline \multicolumn{6}{|c|}{ Informações } \\
\hline \multirow{6}{*}{ 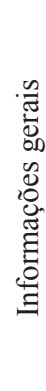 } & Semestres & 2016.1 & 2016.2 & 2017.1 & 2017.2 \\
\hline & Dias & Segundas e quartas & \multicolumn{3}{|c|}{ Segundas e quartas } \\
\hline & Horários das aulas & $\begin{array}{l}\text { Turma } 1-15: 00 \text { às } 16: 00 \\
\text { Turma } 2-16: 00 \text { às 17:00 } \\
\text { Turma } 3-17: 00 \text { às 18:00 }\end{array}$ & \multicolumn{3}{|c|}{$\begin{array}{l}\text { Turma } 1-15: 00 \text { às } 16: 30 \\
\text { Turma } 2-16: 30 \text { às 18:00 }\end{array}$} \\
\hline & Formato das aulas & 60 minutos de prática & \multicolumn{3}{|c|}{$\begin{array}{l}30 \text { minutos de discussão de textos } \\
60 \text { minutos de prática }\end{array}$} \\
\hline & Quantidade de encontros & 24 & 24 & 25 & 24 \\
\hline & Quantidade de horas & $72 \mathrm{~h} / \mathrm{a}$ & $72 \mathrm{~h} / \mathrm{a}$ & $75 \mathrm{~h} / \mathrm{a}$ & $72 \mathrm{~h} / \mathrm{a}$ \\
\hline
\end{tabular}

Fonte: Ação de extensão "Yoga e Cultura de Paz na FACED”

Org.: Pricila Aragão 
As aulas foram ministradas na sala de Arte e Educação da FACED, pois o espaço possuía uma estrutura especial com mesas móveis e cadeiras empilháveis, além de piso emborrachado, permitindo a mobilidade necessária (embora não ideal) para a adequação do espaço às atividades, porém com espaço reduzido, limitando o número de participantes.

Por se tratar de uma pesquisa para a constituição de uma tese de doutorado, durante a ação de extensão foram elaborados, ao longo dos dois anos da ação, vários instrumentos para a coleta de dados qualitativos, como questionários, entrevistas e análise documental (LÜDKE; ANDRÉ, 1986; MATOS; VIEIRA, 2001; ROSA; ARNOLDI, 2006; OLIVEIRA, 2008). Para o recorte analisado neste artigo, foram utilizados os dados obtidos através da ficha de inscrição (no total de 190 fichas) e do questionário de avaliação (com 26 preenchimentos) de um ano do projeto.

A seguir, descreveremos o perfil dos participantes inscritos para a ação, de acordo com os dados fornecidos na ficha de inscrição mencionada acima e, logo após, serão analisadas as perguntas feitas no questionário eletrônico de avaliação, para entender como os participantes assimilavam os conhecimentos teóricos, bem com os valores humanos imersos no trabalho da ação de extensão desenvolvida.

\section{RESULTADOS}

\section{Perfil dos participantes}

De acordo com os dados obtidos através da ficha de inscrição, a maioria dos interessados em participar do projeto possuíam uma faixa etária entre 23 e 59 anos, sendo $80 \%$ destes mulheres e $20 \%$ homens. A maioria possuía vínculos com a universidade como estudantes de graduação (totalizando $65 \%$, entre cursos como pedagogia, biblioteconomia, letras, ciências biológicas e música) e estudantes de pós-graduação (totalizando 24\%, de mestrado e doutorado em educação, antropologia e letras, por exemplo). Em menor quantidade $(11 \%)$, percebemos pessoas que não possuem vínculo estudantil com a universidade, alunos já formados, professores e servidores da UFC. Relacionamos a seguinte composição do grupo devido ao processo de divulgação da ação de extensão, predominantemente realizado dentro da Faculdade de Educação através de cartazes e da divulgação entre os alunos do projeto para amigos e familiares. A divulgação foi realizada em escala reduzida devido à limitada quantidade de vagas e à impossibilidade de atender a todos os interessados.

Ao serem questionados sobre o estado geral de saúde, temos duas respostas predominantes: $32 \%$ relatam não apresentarem quaisquer problemas de saúde enquanto $68 \%$ indicou possuir problemas de saúde (físicos e psicoemocionais) como depressão, ansiedade, dores na coluna e articulações (como ombro e joelhos), hérnia de disco, obesidade, labirintite e enxaqueca, por exemplo. Muitos dos que relataram possuir tais enfermidades também indicaram tomar medicamentos para tais doenças. Os problemas de saúde acima podem ser atribuídos aos elevados níveis de estresse do cotidiano, e chamamos a atenção para o proeminente número de estudantes (tanto de graduação como de pós-graduação) com os relatos de alta incidência de questões relacionadas à ansiedade, depressão, dores na coluna e distúrbios alimentares.

Sobre os motivos que os direcionaram para a prática de yoga, temos a busca por autoconhecimento, a vontade de aprofundar os conhecimentos sobre o tema, o anseio por diminuir o estresse do dia a dia e a mitigação de doenças associadas ao estresse, como as já descritas. Também foram relatadas a necessidade de alinhar corpo e mente e a busca por uma atividade que transcendesse o aspecto físico, atuando também como um processo de reencontro e busca espiritual.

O conhecimento sobre a filosofia e prática do yoga são variáveis entre os inscritos, oscilando desde pessoas que já praticaram alguma modalidade (37\%) por determinado período (seja ele de semanas a anos), a indivíduos que só ouviram falar, sem nenhum aprofundamento e autodidatas que não haviam frequentado aulas de yoga com professores, utilizando livros ou vídeos para o contato (totalizando 63\%). Vários participantes relataram possuir interesse ou aproximações com outras práticas terapêuticas, espiritualistas e de autoconhecimento como a meditação, o reiki, o ayahuasca, a massoterapia e a musicoterapia, dentre outros. A heterogeneidade do grupo apresentou-se como uma característica riquíssima para possibilitar diálogos e a troca de experiências entre os participantes, permitindo que todos trabalhassem e evoluíssem juntos.

A idealização da ação partiu da preocupação em tornar a vivência da extensão em um projeto dialógico 
de construção de saberes na coletividade, aliando os conhecimentos tradicionais do yoga com vivências pessoais e diálogos interpessoais, com o objetivo de perceber e transformar o modo como cada integrante se relacionava consigo, com seus pares e com o mundo, através do discurso dos participantes. Por esse motivo, desde o primeiro encontro tentamos construir uma relação dialógica, de troca e desenvolvimento mútuo, como a tomada de decisões a partir de discussões e deliberações coletivas, que se mostrou ser um aspecto fundante do grupo de Yoga e Cultura de Paz na FACED.

Os diálogos presenciais foram acompanhados por comunicação via e-mail (para o compartilhamento de informes e arquivos) e por whatsapp (para interações rápidas), buscando interligar o universo do yoga e da cultura de paz.

Acreditamos que a ação de extensão desenvolvida carregou em si a possibilidade de estimular reflexões sobre a vivência do yoga numa perspectiva espiritual capaz de fomentar o desenvolvimento de uma cultura de paz, transformando a relação que os indivíduos nutrem consigo, em suas relações interpessoais e com o mundo.

Buscou-se, através dessas aulas, não somente oferecer uma prática terapêutica benéfica ao corpo e à mente, mas sobretudo estimular a práxis, o desenvolvimento igualitário entre teoria e prática, capaz de tornar o indivíduo consciente de si para que possa fazer a leitura do mundo de modo mais claro e lúcido, para poder agir e transformá-lo. Pois, segundo Freire (2014, p. 192) "Esse exercício para diminuir a distância entre o meu discurso e a minha prática se chama qualidade ou virtude da coerência, sem a qual o trabalho pedagógico se acaba. Eu diria até sem a qual a gente se perde". Desse modo, o trabalho pedagógico almejou a coerência ao transcender a esfera cognitiva ou afetiva isoladamente, criando assim uma esfera da integralidade do ser humano ao diminuir distâncias, facilitar diálogos, mediar contatos entre os indivíduos e o mundo, busca-se difundir a igualdade, a solidariedade, a justiça social e a amorosidade, fundamentais para o desabrochar de uma cultura de paz.

\section{A PROMOÇÃO DA PAZ}

Nessa seção, trazemos os dados obtidos no questionário submetido aos alunos após um ano de atividade da ação de extensão. O intuito foi entender a percepção dos participantes acerca dos conhecimentos teóricos sobre os conceitos abordados, além de problematizar a assimilação dos valores humanos imersos na ação de extensão desenvolvida.

Destacamos, entre as perguntas, três que se relacionam diretamente com a análise proposta nesse artigo: 1. O que você entende por paz? 2. Você acredita que o Yoga possui um papel na construção de uma Cultura de Paz? 3. Na sua opinião, qual a relevância de um projeto sobre Cultura de Paz e Yoga em uma Universidade Federal?

A primeira questão buscou entender a percepção que os participantes tinham sobre a paz, como forma de balizar as perguntas seguintes. Algumas respostas estão registradas a seguir:

Paz é quando se vive em paz consigo mesmo e com os outros. É querer e fazer o bem aos outros.

Paz é a existência de sentimentos em nós que nos ajudam a cuidar melhor de nós, das pessoas e de tudo que existe no mundo, visando o bem de todos.

Entendo que é estar tranquilo quanto a quem você é, ao que faz ao outro e ao seu papel no mundo.

As respostas acima se alinham com a proposição de Weil (1993), uma vez que o autor entende que a paz se consolida a partir de três eixos: o indivíduo (como arte de viver em paz consigo mesmo), a sociedade (como arte de viver em paz com os outros) e a natureza (como arte de viver em paz com a natureza). Grande parte das respostas é representada pela visão da tríade da paz (eu, outro e mundo), ilustrada pelas afirmações acima citadas, provavelmente devido ao enfoque holístico defendido durante as aulas e discussões teóricas, buscando sempre ter uma visão ampla e integral dos processos que dialogam com a existência humana. Desse modo, estar em paz não é ter uma análise estritamente individual e isolada das questões sociais e ambientais, e sim se colocar de modo aberto, sereno e firme para a construção de uma paz que abranja as três dimensões citadas.

Porém, não raro, encontramos na sociedade indivíduos que não puderam ter esse debate crítico e acreditam que quando se fala de paz a base referida é individual e alienada, a pax romana, como Jares (2007) critica, pois essa seria a paz da negação de 
conflitos. Assim, o depoimento a seguir esclarece sobre a Paz numa perspectiva mais ampla:

Paz para mim é um estado de tranquilidade, de aceitação, mas sem passividade. Um estado de paz seria um estado em que todos poderiam conviver bem, respeitando as diferenças, ouvindo o outro, tendo seu espaço, sua voz, evitando conflitos desnecessários. Aprendi este semestre, com as leituras, que podemos usar a nossa indignação com alguns problemas como combustível para a ação, o que não necessariamente indica um comportamento agressivo. Antes tinha a ideia de que se você queria lutar pelo bem, pela paz, acabaria tendo que assumir uma postura mais serena, que poderia se confundir com não-ação, conformação, passividade. Gosto muito também do conceito de paciência (paz-ciência), que é algo tão importante para acalmarmos nossa mente, e lidar com a ansiedade, algo que ainda está muito presente na minha vida.

A resposta acima ilustra, com clareza, a mudança de percepção que transforma o ideal da paz idílica na perspectiva da paz enquanto busca por uma ação transformadora de uma realidade opressora. Desse modo, pensamos que cultivar a paz é trabalhar simultaneamente na perspectiva individual, social e ambiental, pois as três dimensões são indissociáveis. Trata-se, portanto, de refletir sobre como podemos incorporar a educação para a paz no nosso cotidiano, de modo a fomentar uma construção crítica, dialógica e pacífica dos ambientes em que transitamos.

A segunda pergunta foi feita para procurar entender como os participantes se apropriavam das vivências durante as aulas de yoga e relacionavam tais práticas com o desenvolvimento de uma cultura de paz.

Sem dúvida, pois por proporcionar uma busca pelo autoconhecimento, passamos a nos ver de uma forma diferente, passamos a ver as outras pessoas com outros olhos. Tentamos nos enxergar como parte de um todo, nos percebemos todos em um processo de aprendizagem, em que podemos crescer muito mais em um estado de paz e respeito mútuo.

Praticar yoga ajuda você a refletir e repensar atitudes, escutar seu coração, mente e espírito. Acredito que praticar não só as posições como a filosofia e os ensinamentos pode, sim, contribuir para acordar as pessoas para a necessidade de mudança de atitudes.
As respostas acima trazem a questão do autoconhecimento como fundamental para o posicionamento no mundo e durante as vivências, o papel da auto-observação foi essencial para permitir que os participantes pudessem reavaliar os aspectos da vida pessoal e do trabalho, de modo mais claro e consciente. A partir desse primeiro movimento foi possível perceber como os indivíduos respondiam a situações do cotidiano (como estresse, imprevistos e decepções) e o efeito que estas possuíam no nível psicofísico, bem como afetavam as relações interpessoais. Nesse sentido, aprender a se perceber e se entender é visto como o primeiro passo para a busca de um sentido mais profundo de paz, que possa atuar de modo pleno e significativo para cada um.

Indubitavelmente, pois o Yoga nos convida a estarmos em nosso aqui e agora, a habitar nosso corpo físico e, ao mesmo tempo, habitar o corpo social do qual fazemos parte. A prática de Yoga nos (e)leva ao exercício de (auto)compaixão e nos tira da zona de conforto de um "buscador espiritual" ilhado em si mesmo e nos põe de cara para nossas tarefas no e para o mundo. A troca de gentilezas entre o yogi e seu corpo pode espraiar para a prática da gratidão na vida. O exercício de paciência consigo mesmo nas práticas do ásanas é o mesmo que fazemos na vida. Arrisco-me a dizer que mundo seria mais sereno, mais silencioso e mais presente se todos praticássemos Yoga.

$\mathrm{Na}$ resposta acima, fica clara a transição entre o eu - outro - mundo, passeando entre as três dimensões que constituem a busca e promoção da paz. Um modo interessante de se perceber essa tríade da paz é fazer como sugere Guimarães (2003), ao propôr que uma das maneiras de romper a idealização acerca da noção de paz é inseri-la nas relações do cotidiano, percebendo-a dinâmica na reapropriação do conceito pelo indivíduo e pela coletividade. Segundo o autor, para superar o ideal de passividade ou permissividade que reside no conceito é preciso transpor a teorização excessiva e irreflexiva sobre a praticidade e cotidianidade do conceito.

A terceira pergunta envolve a relevância do desenvolvimento de um projeto de Cultura de Paz e Yoga em uma Universidade. Esse tópico emerge da necessidade de pensar em iniciativas que promovam o bem-estar físico, mental e espiritual tanto de alunos de graduação e pós-graduação quanto da comunidade na 
qual os centros educativos se inserem. Como descrito no tópico anterior, muitos participantes procuraram as aulas de yoga por possuírem demandas psicofísicas ligadas ao cotidiano estressante e desejarem apoio e inserção em um grupo capaz de resgatar aspectos desconectados da vida.

Como o nome já sugere, a Universidade é um universo de possibilidades e entre elas, cultivar a Cultura de Paz é uma das possibilidades mais urgentes, pois a instituição, por ser um ambiente de pesquisa e muita racionalização científica, carece de espiritualidade. Não me refiro à espiritualidade, necessariamente, ligada às religiões, mas à prática da tolerância e do despertar de uma consciência amorosa diante da vida e dos que dividem o espaço universitário conosco.

Muito significativa principalmente porque nós estudantes estamos sempre no limite do stress e a prática da Yoga nos trazer de volta para o que temos de melhor em nós mesmo, nós traz a paz que nos conecta com Deus o universo e a natureza devolvendo em nós a capacidade de ser mais humano trabalhando por um mundo melhor repleto de amor e solidariedade.

As respostas resgatam a problemática apresentada no início do artigo, ao evidenciar o ambiente acadêmico como um espaço de racionalização excessiva e frequente desvalorização dos demais saberes, como o emocional, corporal e espiritual. Tornar o espaço da universidade mais representativo e humano faz com que o mesmo possa desempenhar suas funções intelectuais de maneira mais satisfatória, pois fundamenta-se no respeito pela constituição plural dos indivíduos.

Desse modo, a ação de extensão tornou-se um grupo de apoio e fortalecimento da saúde física e mental dos participantes, como proposto recentemente por Evans et al. (2018), pois foi construído um ambiente de acolhimento e confiança, onde os indivíduos se sentiam confortáveis para relatar problemas e buscar soluções para os mesmos.

Com base nessas três perguntas e respostas associadas, percebemos que a promoção da paz e da saúde mental é um processo que envolve as dimensões individuais, interpessoais e ambientais, porém, que é possível fomentá-la a partir de um projeto pensado e desenvolvido com esses objetivos. O referencial teórico, a metodologia utilizada e, sobretudo, a vivência do cotidiano devem dialogar com tais pressupostos para que se estabeleça o ambiente de saúde psicofísica fundamental para o florescimento de uma cultura de paz.

\section{REFLEXÕES}

De acordo com os dados, $89 \%$ dos inscritos possuíam vínculo com o ambiente acadêmico e $68 \%$ relataram problemas de saúde (física ou mental). Tais dados evidenciam a importância de promover iniciativas que estimulem o autocuidado e advoguem por uma nova cultura no modo de fazer ciência, criando o ambiente de bondade, sugerido por Powell (2018). Woolston (2018) afirma que aumentar a qualidade de vida das pessoas é aumentar a qualidade da pesquisa realizada por elas, e entendemos que tal afirmação pode ser extrapolada para todos os setores da vida, teorizando que pessoas felizes e saudáveis tendem a realizar suas atividades (pessoais e de trabalho) de modo mais eficiente e contribuindo para o bem-estar individual e interpessoal.

Para que a semente dessa nova cultura da universidade possa ser plantada e floresça, pesquisadores como Powell (2017, 2018), Evans et al. (2018) e Woolston (2018) sugerem a criação de ambientes de suporte, onde os membros da academia possam encontrar a empatia e o apoio necessários para compartilhar anseios, dúvidas e dificuldades, criando uma comunidade de apoio onde os indivíduos possam cuidar uns dos outros. A criação desde ambiente se deu, na presente pesquisa, através do grupo formado pelos participantes da ação de extensão, onde foi possível estimular e dar suporte ao crescimento de cada indivíduo, mediado pelo estudo do yoga, da cultura de paz e pela busca por autoconhecimento.

Sugerimos, em concordância com Levecque et al. (2017), Evans et al. (2018) e Woolston (2018), o desenvolvimento de mais pesquisas nessa área, de modo a criar estratégias de intervenção que possibilitem o cuidado com a saúde física, mental e emocional (de graduandos, pós-graduandos da comunidade). Para isso, recomenda-se a realização de investigações em outras áreas de conhecimento da universidade, abrangendo os centros de ciência, tecnologia, saúde e humanas, e com grupos maiores, possivelmente inserindo pesquisas quantitativas para dar o suporte necessário ao desenvolvimento de políticas e estratégias de mediação. 
Diante do exposto, percebemos a necessidade de incentivar momentos e práticas de autocuidado, autoconhecimento e promotoras da paz no ambiente acadêmico, devido ao seu perfil excessivamente racional que põe em segundo plano o desenvolvimento emocional, corporal e psicológico.

Precisamos trazer à luz questionamentos sobre o tipo de ambiente acadêmico (ou escolar, por exemplo) que temos intenção de criar, pois trata-se de uma abordagem complexa, desde a reavaliação da postura assumida nos interstícios da academia e como lidamos com o estresse habitualmente gerado, aos direcionamentos e relações construídos com relação à pesquisa e aos pesquisadores envolvidos (que podem ser saudáveis ou não) e, por último, como construímos espaços (físicos ou simbólicos) de reflexão, suporte e cura.

A prática regular de yoga (bem como outras práticas espirituais que promovem o autoconhecimento) pode favorecer o bem-estar físico, psicológico e emocional dos praticantes, porém suas potencialidades transcendem o aspecto individual ao estimularem a busca por autoconhecimento e novas formas de inserção no mundo, pautadas pela busca por igualdade, solidariedade, companheirismo e amorosidade.

Estimular o yoga como forma de conexão, desde que enraizado na tradição e com o estímulo à leitura crítica da realidade, é estimular uma cultura de paz com a potencialidade em diminuir distâncias entre os indivíduos e criar redes de apoio capazes de pensar novas formas de construção da sociedade, embasadas em ideais de bem comuns. Nesse sentido, essa pesquisa escolheu o espaço acadêmico para plantar e disseminar a cultura de paz, na esperança de presenciar o florescer dessa nova maneira de perceber o universo (interior e exterior).

É importante salientar, contudo, que outras práticas integrativas podem ser desenvolvidas objetivando a obtenção de resultados similares, desde que tais práticas ou terapias (por exemplo, a tessitura de mandalas e o reiki, ambos desenvolvidos no projeto de extensão ao qual a ação com o yoga pertenceu) envolvam uma leitura simultaneamente crítica, questionadora e transformadora da realidade. Isso implica no envolvimento ativo do participante para entender a situação na qual se encontra, como um modo de autoconhecimento, e o compromisso de engajamento para modificá-la em benefício seu e de seus pares.
Esse artigo também buscou incentivar o desenvolvimento de outras iniciativas voltadas para este ambiente acadêmico, pensadas para suprir as necessidades e anseios de seus participantes, de modo a mitigar e procurar soluções para as vicissitudes do cotidiano. Acreditamos, por fim, que o cultivo de uma cultura de paz é capaz de trazer respostas para as demandas individuais e sociais que experienciamos na atualidade.

\section{AGRADECIMENTOS}

À CAPES, pela bolsa de doutorado concedida a Pricila Cristina Marques Aragão, ao Grupo de Pesquisa em Cultura de Paz, e a todos os envolvidos na realização do Projeto de Extensão em Cultura de Paz na FACED (Faculdade de Educação da Universidade Federal do Ceará): Ações de Educação, Espiritualidade e Saúde.

Ao Centro de Estudos Sociais (CES) da Universidade de Coimbra, Portugal, onde a Prof ${ }^{\text {a. }}$ Dra. Kelma Socorro Lopes de Matos está cursando o Pós Doutorado e desenvolvendo estudos sobre a Cultura de Paz e o Projeto de Extensão na FACED - UFC.

\section{REFERÊNCIAS BIBLIOGRÁFICAS}

ARENAZA, D. E. M. O yoga na sala de aula. Cadernos de Yoga, Florianópolis, v. 1, p. 11-14, verão, 2004.

ARORA, H. L. Terapias Quânticas: Cuidando do ser inteiro. Rio de Janeiro: Qualitymark, 2013.

BABA, P. Transformando o sofrimento em alegria. Fortaleza: Editora Demócrito Dummar, 2014.

BROWN, C. O livro do yoga. São Paulo: DCL, 2011.

DUARTE JR. J. F. O sentido dos sentidos: a educação (do) sensível. Curitiba: Criar, 2001.

EVANS, T. M.; BIRA, L.; GASTELUM, J. B.; WEISS, T.; VANDERFORD, N. L. Evidence for a mental health crisis in graduate education. Nature Biotechnology. v. 36, n. 3, p. 282-284, 2018.

FREIRE, P. Pedagogia do oprimido. Rio de Janeiro: Paz e Terra, 2011a.

FREIRE, P. Pedagogia da autonomia: saberes necessários à prática educativa. São Paulo: Paz e Terra, 2011 b.

FREIRE, P. Pedagogia da tolerância. Rio de Janeiro: Paz e Terra, 2014. 
GIL, A. C. Métodos e técnicas da pesquisa social. São Paulo: Editora Atlas S. A., 1999.

GUIMARÃES, M. R. Educação para a paz: sentidos e dilemas. Caxias do Sul: Educs, 2011.

HENDRY, L. Sitting down with R. Sharath Jois. LA Yoga Magazine, 16 may 2016. Disponível em: https://ayoga.com/ community/teacher-profiles/sitting-down-with-r-sharathjois/. Acesso em: 4 jan. 2017.

GUIMARÃES, M. R. Uma escola para a paz: a educação em tempos de violência. Revista Prospectiva, Porto Alegre, n. 27, p. 13-24, 2003.

HERMÓGENES, J. Yoga para nervosos. Rio de Janeiro: Nova Era, 2007.

HERMÓGENES, J. Autoperfeição com Hatha Yoga: um clássico sobre saúde e qualidade de vida. $50^{\mathrm{a}}$ ed. Rio de Janeiro: Nova Era, 2010.

IYENGAR, B. K. S. Luz na vida: a jornada da ioga para a totalidade, paz interior e a liberdade suprema. São Paulo: Summus, 2007.

JARES, X, R. Educação para a paz: sua teoria e sua prática. Porto Alegre, Artmed, 2002.

JARES, X. R. Educar para a verdade e para a esperança: em tempos de globalização, guerra preventiva e terrorismos. Porto Alegre, Artmed, 2005.

JOIS, K. P. Yoga Mala. New York: North Point Press, 2010.

LEVECQUE, K.; ANSEEL, F.. DE BEUCKELAER, A.; VAN DER HEYDEN, J.; GISLE, L. Work organization and mental health problems in $\mathrm{PhD}$ students. Research Policy. v. 46, p. 868-879, 2017.

LÜDKE, M.; ANDRÉ, M. E. D. A. Pesquisa em educação: abordagens qualitativas. São Paulo: EPU, 1986.

MATOS, K. S. L. de M.; VIEIRA, S. L.Pesquisa Educacional: o prazer de conhecer. Fortaleza: Edições Demócrito Rocha, 2001.

MINAYO, M. C. de S. O desafio da pesquisa social. In: MINAYO, Maria Cecília de Souza;

GOMES, Suely Ferreira Deslandes Romeu (org.). Pesquisa social: teoria, método e criatividade. $29^{\mathrm{a}}$ ed. Petrópolis: Vozes, 2010.

OLIVEIRA, M. M. de. Como fazer pesquisa qualitativa. Petrópolis: Vozes, 2008.

PACKER, M. L. G. A senda do Yoga. Blumenau: Nova Letra, 2009.

POWELL, K. Break or burn-out. Nature, v. 545, p. 375-377, 2017.

POWELL, K. A kinder kind of science. Nature, v. 552, n. 18, p. $367-369,2018$.
ROSA, M.V. F. P. C.; ARNOLDI, M. A. G. C. A entrevista na pesquisa qualitativa: Mecanismo para validação dos resultados. Belo Horizonte: Autêntica, 2006.

THIOLlENT, M. Metodologia da pesquisa-ação. São Paulo: Cortez, 2011.

WEIL, P. A arte de viver em paz: por uma nova consciência, por uma nova educação. São Paulo: Gente, 1993.

WOOLSTON, C. Faking it. Nature, v. 529, p. 555-557, 2016.

WOOLSTON, C. A love-hurt relationship. Nature, v. 550, n. 26, p. 549-552, 2017.

WOOLSTON, C. Why mental health matters. Nature, v. 557, p. 129-131, 2018. 